\title{
Molecular cloning, sequence characterization, and gene expression profiling of a novel water buffalo (Bubalus bubalis) gene, AGPAT6
}

\author{
S. Song1*, J.L. Huo ${ }^{1 *}$, D.L. Li ${ }^{2,3 *}$, Y.Y. Yuan ${ }^{2}$, F. Yuan ${ }^{1}$ and Y.W. Miao ${ }^{1}$ \\ ${ }^{1}$ Faculty of Animal Science and Technology, Yunnan Agricultural University, \\ Kunming, Yunnan, China \\ ${ }^{2}$ Domestic Animal Breeding and Crossbreed-improvement Station of Yunnan \\ Province, Kunming, Yunnan, China \\ ${ }^{3}$ Yunnan Institute of BAFULE Buffalo Science and Technology, \\ Kunming, Yunnan, China \\ *These authors contributed equally to this study. \\ Corresponding author: Y.W. Miao \\ E-mail: yongwangmiao999@163.com / miaoyw1@ynau.edu.cn
}

Genet. Mol. Res. 12 (4): 4116-4126 (2013)

Received March 3, 2013

Accepted August 15, 2013

Published October 1, 2013

DOI http://dx.doi.org/10.4238/2013.October.1.2

\begin{abstract}
Several 1-acylglycerol-3-phosphate- $O$-acyltransferases (AGPATs) can acylate lysophosphatidic acid to produce phosphatidic acid. Of the eight AGPAT isoforms, AGPAT6 is a crucial enzyme for glycerolipids and triacylglycerol biosynthesis in some mammalian tissues. We amplified and identified the complete coding sequence (CDS) of the water buffalo AGPAT6 gene by using the reverse transcription-polymerase chain reaction, based on the conversed sequence information of the cattle or expressed sequence tags of other Bovidae species. This novel gene was deposited in the NCBI database (accession No. JX518941). Sequence analysis revealed that the CDS of this AGPAT6 encodes a 456-amino acid enzyme (molecular mass = $52 \mathrm{kDa}$; pI = 9.34). Water buffalo AGPAT6 contains three hydrophobic transmembrane regions and a signal 37-amino acid peptide, localized
\end{abstract}


in the cytoplasm. The deduced amino acid sequences share 99, 98, $98,97,98,98,97$ and $95 \%$ identity with their homologous sequences from cattle, horse, human, mouse, orangutan, pig, rat, and chicken, respectively. The phylogenetic tree analysis based on the AGPAT6 CDS showed that water buffalo has a closer genetic relationship with cattle than with other species. Tissue expression profile analysis shows that this gene is highly expressed in the mammary gland, moderately expressed in the heart, muscle, liver, and brain; weakly expressed in the pituitary gland, spleen, and lung; and almost silently expressed in the small intestine, skin, kidney, and adipose tissues. Four predicted microRNA target sites are found in the water buffalo AGPAT6 CDS. These results will establish a foundation for further insights into this novel water buffalo gene.

Key words: Water buffalo; Isolation; Bioinformatic analysis; 1-Acylglycerol-3-phosphate- $O$-acyltransferase 6 (AGPAT6);

Tissue expression profile

\section{INTRODUCTION}

The $s n$-1-acylglycerol-3-phosphate- $O$-acyltransferase (AGPAT) enzyme is crucial in de novo triacylglycerol synthesis in eukaryotes (Takeuchi and Reue, 2009). It catalyzes the second step by acylating lysophosphatidic acid to phosphatidic acid (Aguado and Campbell, 1998; Coleman and Lee, 2004; Ye et al., 2005; Agarwal et al., 2006, 2007; Nagle et al., 2008; Sukumaran et al., 2009). So far, eight members of the AGPAT gene family have been described in humans, which are AGPAT1-8, and each of them possesses a lysophosphatidic acid acyltransferase motif (Ye et al., 2005; Nagle et al., 2008). As a member of the AGPAT family, AGPAT6 appears to play a key role in lipid biosynthesis (Chen et al., 2008). After careful examination of the AGPAT enzyme activity by Chen et al. (2008) and Nagle et al. (2008), the enzyme was recognized as another endoplasmic reticulum-localized glycerol phosphate acyltransferase (GPAT) and renamed as GPAT4. The AGPAT6 gene has recently been identified in humans, mice, cattle, and chickens (Li et al., 2003; Chen et al., 2008; Zimin et al., 2009). In both human and mouse, the AGPAT6 gene consists of 13 exons, whereas that in cattle and chicken contains 12 exons. The AGPAT6 protein contains 456 amino acids (aa) in the species mentioned above, except chicken, in which it is composed of 455 aa ( $\mathrm{Li}$ et al., 2003; Beigneux et al., 2006; Chen et al., 2008; Nagle et al., 2008).

Study using AGPAT6-deficient mice showed that the milk produced from them was markedly depleted in diacyglycerols and triacylglycerols, and AGPAT6 is crucial for the production of milk fat by the mammary gland (Beigneux et al., 2006). The polymorphisms of AGPAT6 were highly significantly associated with the milk fat percentage estimated breeding values in the German Holstein-Friesian population, as shown in a recent research (Wang et al., 2012). The result of a study by Nafikov (2010) showed that AGPAT6 was associated significantly with large differences in the compositions of milk fat, such as concentrations of saturated fatty acids, unsaturated fatty acids, monounsaturated fatty acids, and so on. 
AGPAT6, which was identified on Bos taurus autosome 27, is a pivotal gene related to catalytic biosynthesis of glycerolipids. It coordinately regulates the channeling of fatty acids toward copious milk fat synthesis in bovine mammary (Bionaz and Loor, 2008a). Therefore, AGPAT6 can be considered as a potential gene involved in regulating the milk fat composition in dairy cattle. Water buffalo contributes significantly to the agricultural economy and dairy industry in the tropical and subtropical countries (Singh et al., 2000; Khan et al., 2011; Perera, 2011). It is the second largest source of milk supply in the world, and buffalo milk contains less water and more fat, lactose, protein, and minerals than cow milk (Vijh et al., 2008; Mahmood and Usman, 2010; Yindee et al., 2010). However, the AGPAT6 gene in water buffalo has not yet been isolated and characterized, and its tissue expression has not been clear to date. In the current study, we isolated the full-length coding sequence of the water buffalo AGPAT6 gene, based on the reverse transcription-polymerase chain reaction (RT-PCR). We also analyzed its primary structure, and displayed the tissue distribution of its expression. The data obtained will serve as a basis for understanding the water buffalo AGPAT6 gene.

\section{MATERIAL AND METHODS}

\section{Sample collection, RNA extraction, and first-strand complementary DNA (cDNA) synthesis}

The fresh tissue samples, which included the heart, pituitary gland, small intestine, muscle, spleen, liver, mammary gland, skin, lung, brain, kidney, and fat, were collected from three Binglangjiang water buffalo after they had been slaughtered. The samples were snapfrozen immediately in liquid nitrogen and then stored at $-80^{\circ} \mathrm{C}$ before processing for RNA isolation. Total RNA was extracted using RNAiso Plus (TaKaRa, Dalian, China) according to the manufacturer instructions. To remove genomic DNA contamination, total RNA was digested with RNase-free DNase I (TaKaRa). The total RNA $(1 \mu \mathrm{L})$ was checked by electrophoresis on a $2.0 \%$ agarose gel containing ethidium bromine. The RNA $(3 \mu \mathrm{g})$ was reverse-transcribed with the oligo $(\mathrm{dT})_{18}$ primer and M-MLV reverse transcriptase (Invitrogen, USA).

\section{Isolation of the water buffalo AGPAT6 gene}

The AGPAT6 message RNA (mRNA) sequence for B. taurus (accession No. NM_001083669), available in the National Center for Biotechnology Information (NCBI) database, and its highly homologous expressed sequence tags were used to design a pair of primers to obtain the full-length coding regions of the AGPAT6 gene. The primers amplified for AGPAT6 are listed in Table 1. The PCR was performed to isolate the water buffalo AGPAT6 gene using the pooled cDNAs from the different tissues mentioned above. The $25-\mu \mathrm{L}$ reaction system contained $2.0 \mu \mathrm{L} 50 \mathrm{ng} / \mu \mathrm{L}$ cDNA, $2.0 \mu \mathrm{L} 2.5 \mathrm{mM}$ dNTPs mixed (TaKaRa), $2.5 \mu \mathrm{L}$ 10X Taq DNA polymerase buffer ( $\mathrm{Mg}^{2+}$ Plus), $0.5 \mu \mathrm{L} 10 \mu \mathrm{M}$ forward primer, $0.5 \mu \mathrm{L} 10 \mu \mathrm{M}$ reverse primer, $0.25 \mu \mathrm{L} 5 \mathrm{U} / \mu \mathrm{L}$ Ex Taq DNA polymerase (TaKaRa), and $17.5 \mu \mathrm{L}$ sterile water. The amplification conditions were as follows: $94^{\circ} \mathrm{C}$ for $3 \mathrm{~min}$, followed by 35 cycles of $94^{\circ} \mathrm{C}$ for $30 \mathrm{~s}, 55^{\circ} \mathrm{C}$ for $45 \mathrm{~s}$, and $72^{\circ} \mathrm{C}$ for $2 \mathrm{~min}$, and then a final extension at $72^{\circ} \mathrm{C}$ for $5 \mathrm{~min}$. The amplified fragment was subcloned into the pMD18-T vector (TaKaRa) and then sequenced bidirectionally using the commercial fluorometric method. At least eight independent clones were sequenced. 


\begin{tabular}{|c|c|c|c|c|}
\hline Gene (GenBank No.) & Primers $\left(5^{\prime} \text { to } 3^{\prime}\right)^{1}$ & Amplicon length (bp) & Annealing temperature $\left({ }^{\circ} \mathrm{C}\right)$ & Usage \\
\hline AGPAT6 (NM_001083669) & $\begin{array}{l}\text { F: GGGATGCGAACTTGGGAATG } \\
\text { R: ACTCAGCGGAAAGGGACACA }\end{array}$ & 1585 & 55 & CDS cloning \\
\hline AGPAT6 (NM_001083669) & $\begin{array}{l}\text { F: AACCTGCATCAATAATACATCA } \\
\text { R: GGTAGGTCACCATTCCGTA }\end{array}$ & 146 & 55 & Expression \\
\hline 18S rRNA (JN412502) & $\begin{array}{l}\text { F: GGACATCTAAGGGCATCACAG } \\
\text { R: AATTCCGATAACGAACGAGACT }\end{array}$ & 145 & 55 & Expression \\
\hline
\end{tabular}

${ }^{1}$ Primer direction $(\mathrm{F}=$ forward; $\mathrm{R}=$ reverse $)$.

\section{Software for bioinformatic analysis}

To predict the physical and chemical properties of the putative AGPAT6 protein, the software on the ExPASy server (http://au.expasy.org/) was used. The protein prediction and analysis were performed using the Conserved Domain Architecture Retrieval Tool of BLAST at the NCBI server (http://www.ncbi.nlm.nih.gov/BLAST). The ClustalW software (http://align. genome.jp/) was used for alignment of multiple sequences. The theoretical molecular weight $(\mathrm{Mw})$ and isoelectric point $(\mathrm{pI})$ of these deduced aa of AGPAT6 were computed using the Compute $\mathrm{pI} / \mathrm{Mw}$ (http://us.expasy.org/tools/pi_tool.html) tool. Signal peptides were predicted using the ProP 1.0 server (http://www.cbs.dtu.dk/services/ProP/) and SignalP 3.0 server (http://www.cbs.dtu.dk/services/SignalP-3.0/). PSort II (http://psort.hgc.jp/) was employed to predict protein sorting signals and intracellular localization. Secondary structures of deduced aa sequences were predicted by SOPMA (http://npsa-pbil.ibcp.fr/). Web-based microRNA (MicroRNA) predicting programs were used to locate conversed potential microRNA targets: miRBase (http://www.mirbase.org/). TMHMM Server version 2.0 (http://www.cbs.dtu.dk/ services/TMHMM/) was used to predict transmembrane helices in the proteins. A phylogenetic tree was generated based on AGPAT6 nucleotide sequences by applying the neighbor-joining method in the ClustalX version 2.0 program, which subsequently subjects to be edited manually. Statistical significance of groups within phylogenetic trees was evaluated using the bootstrap method with 1000 replications.

\section{Semiquantitative RT-PCR}

To characterize the AGPAT6 further, semiquantitative RT-PCR was conducted to determine its expression in 12 water buffalo tissues. To eliminate the effect of cDNAs concentration, we repeated the RT-PCR five times using 1, 2, 3, 4, and $5 \mu \mathrm{L}$ cDNAs as templates, respectively. We tested the housekeeping gene $18 \mathrm{~S}$ ribosomal RNA (JN412502) as a positive control. The details of semiquantitative RT-PCRs for AGPAT6 and 18S rRNA amplification are listed in Table 1. PCR analyses were optimized for a number of cycles to ensure product identity within the linear phase of amplification.

\section{RESULTS}

\section{Cloning and identification of water buffalo AGPAT6 complete coding sequence}

The PCR product was a 1585-bp-long fragment (Figure 1), which was consistent with 
expectations. Homology analysis for the sequence obtained in this study was carried out using the BLAST software at the NCBI server. The results showed that the sequence was homologous to the known sequences of the AGPAT6 gene in some species reported. The sequence was then submitted to the NCBI database (accession No. JX518941). The sequence prediction results from the GenScan software analysis showed that a $1371 \mathrm{bp}$ coding sequence represented one single gene, which encoded 456 aa. The complete coding sequence (CDS) of the gene and the deduced aa are presented in Figure 2.

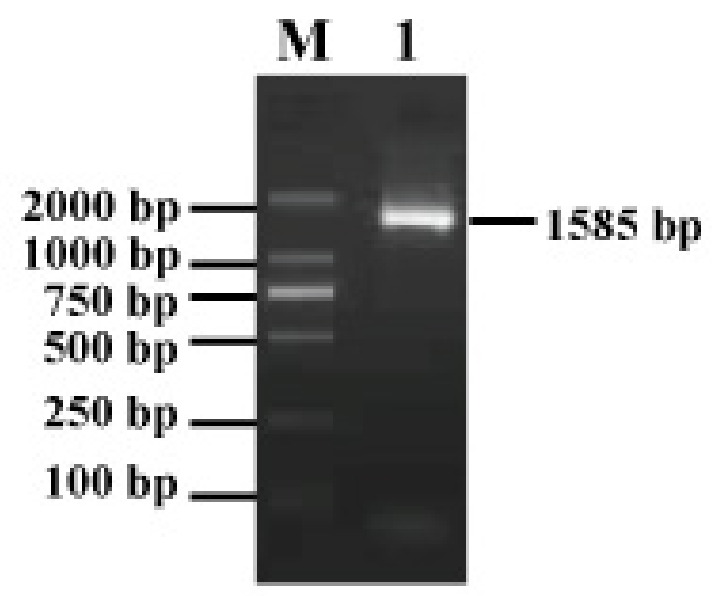

Figure 1. RT-PCR results for water buffalo AGPAT6 gene. Lane $1=$ PCR product for water buffalo AGPAT6 gene and lane $M=$ DL2000 DNA markers.

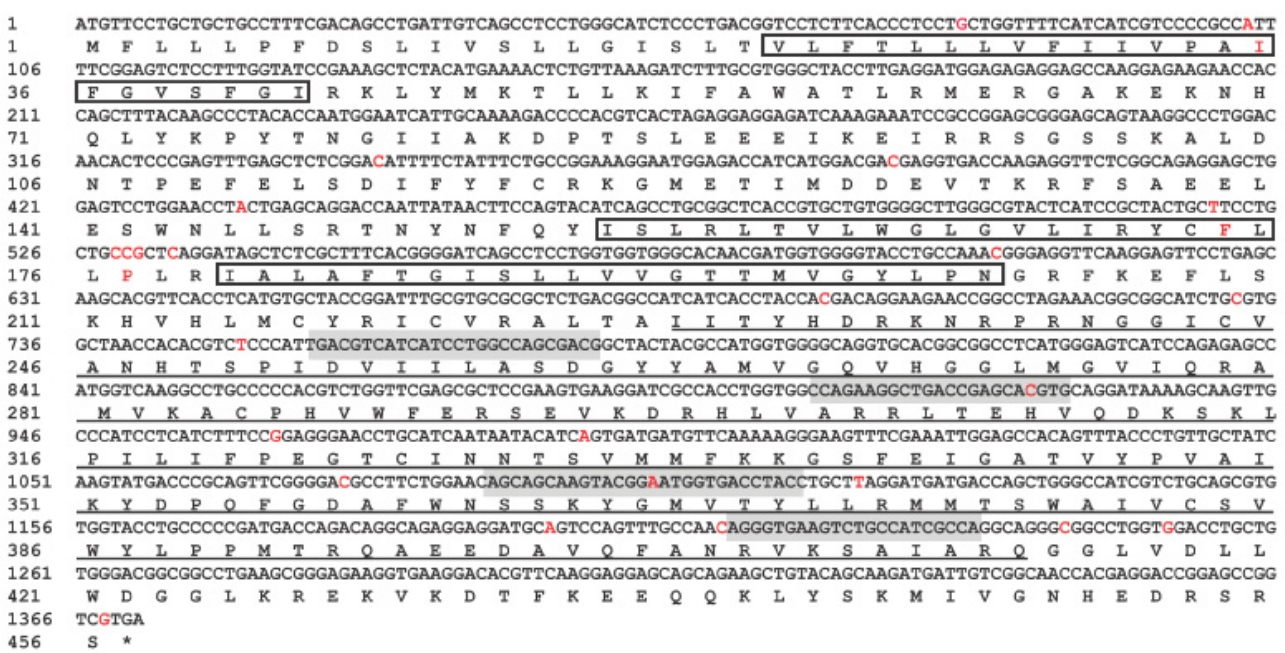

Figure 2. CDS of water buffalo AGPAT6 (accession No. JX518941) and its encoding amino acid sequences. *Stop codon. Conserved domain sequences of LPLAT_LPCAT1-like are underlined. The red characters donate nucleotide difference sites of complete $A G P A T 6$ CDS between water buffalo and cattle. Transmembrane sequences are boxed. MicroRNA target sites predicted are shaded. 


\section{Sequence analysis}

The theoretical $\mathrm{pI}$ and $\mathrm{Mw}$ for the deduced amino acid sequence of water buffalo AGPAT6 were 9.34 and $52 \mathrm{kDa}$, respectively. Hydrophobicity analysis showed water buffalo AGPAT6 to have three putative transmembrane domains (Figure 3). The SignalP 3.0 server analysis showed that AGPAT6 includes an N-terminal signal peptide of 37 aa. The results of cytoplasmic/nuclear discrimination suggested with high reliability (94.1\%) that the water buffalo AGPAT6 function was in the cytoplasm. The conserved domain (LPLAT LPCAT1-like protein domain: 228-IITYHDRGICVANHTSPIDVIILYAMVGQVHGVIQRAMKAHVWFE RSVARRLTEHVPILIFPEGTCINNTSVMMFKKGSFEIGATVYPVAIKYDAFWNSSKYLL RMMTSWAIVCSVWYLPPEDAVQFANRVKSAIARQ-413) was found using BLAST and ClustalW (Figures 2 and 4). Five kinds of modification sites were also found in water buffalo AGPAT6, which include $7 \mathrm{~N}$-myristoylation sites (16-GislTV-21, 37-GvsfGI-42, 99-GsskAL-104,242-GIcvAN-247,267-GQvhGG-272,271-GGlmGV-276,323-GtciNN-328), 6 protein kinase $\mathrm{C}$ phosphorylation sites (58-TIR-60, 100-SsK-102, 132-TkR-134, 157-SIR159, 363-SsK-365, 433-TfK-435), 7 casein kinase II phosphorylation sites (86-TslE-89, 87SleE-90, 125-TimD-128, 136-AaeE-139, 230-TyhD-233, 250-SpiD-253, 433-TfkE-436), 3 cAMP- and cGMP-dependent protein kinase phosphorylation sites (133-KRfS-136, 303RRIT-306, 335-KKgS-338), and $4 \mathrm{~N}$-glycosylation sites (247-NHTS-250, 327-NNTS-330, 328-NTSV-331, 362-NSSK-365). The results of secondary structure prediction indicated that the deduced water buffalo AGPAT6 contains 230 aa alpha helices, 70 aa extend strands, 13 aa beta turns, and 143 aa random coils (Figure 5). Three transmembrane regions were predicted in water buffalo AGPAT6 (Möller et al., 2001) (Figure 6).

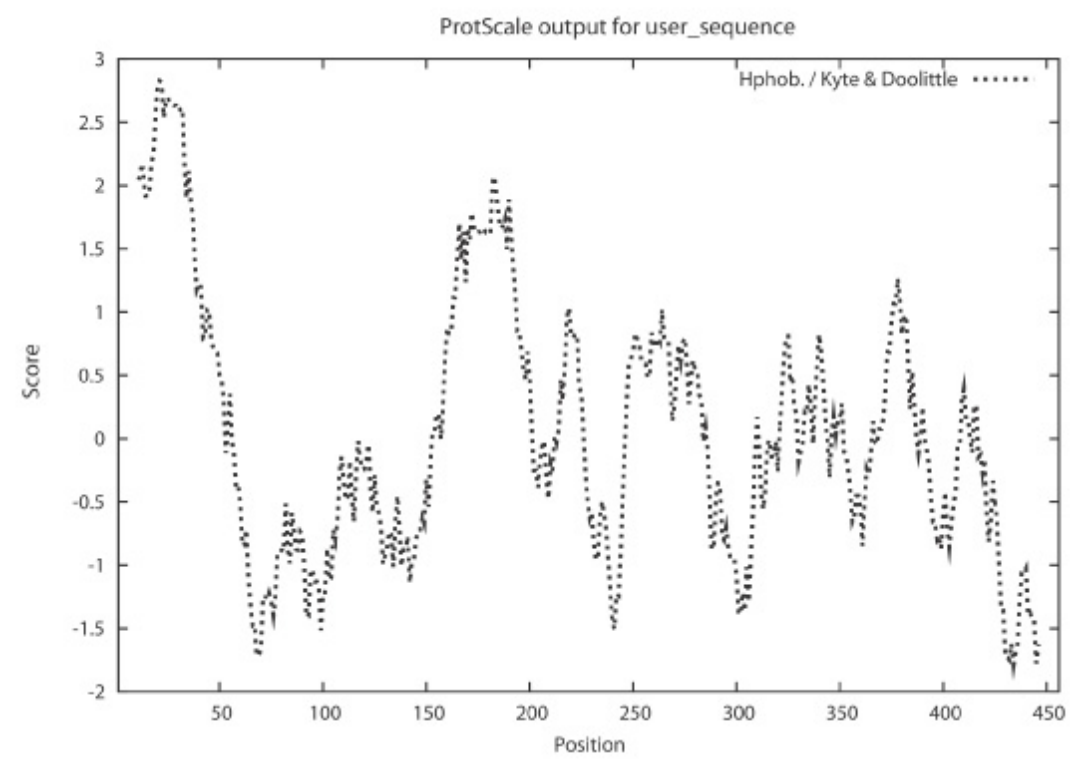

Figure 3. Hydrophobicity structure prediction of water buffalo AGPAT6 by ProtScale. Score $>0$ means hydrophobic; score $<0$ means hydrophilic. 


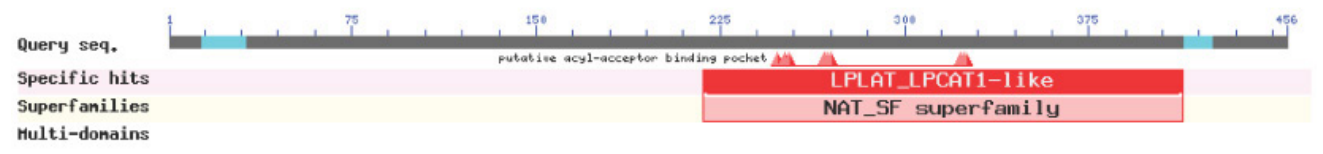

Figure 4. Putative conversed domain of the protein encoded by water buffalo AGPAT6.

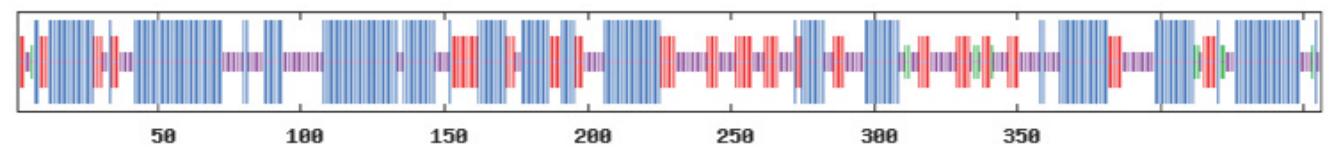

Figure 5. Secondary structure predicted of the water buffalo AGPAT6 protein by SOPMA. Alpha helices, extended strands, beta turn, random coils are indicated with the longest, the second longest, the third longest, and the shortest vertical lines, respectively.

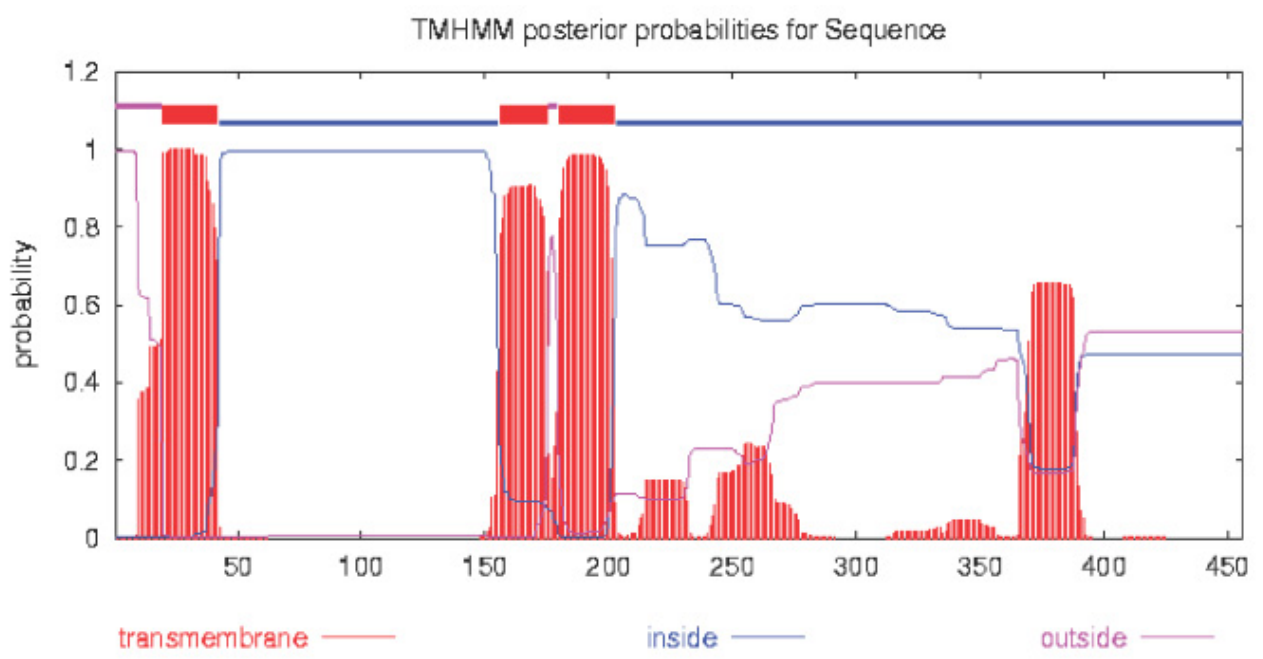

Figure 6. Prediction of transmembrane regions of water buffalo AGPAT6.

\section{Sequence identity and evolutionary relationships of AGPAT6}

The results of similarity comparison revealed that the water buffalo AGPAT6 coding sequence in this study had 99\% identity with that of cattle (NM_001083669). To evaluate the evolutionary relationships of water buffalo AGPAT6 with other species, we constructed a phylogenetic tree using the neighbor-joining method on the basis of the AGPAT6 nucleotide sequences of horse, human, mouse, orangutan, pig, rat, and chicken. Phylogenetic tree analysis showed that the water buffalo AGPAT6 gene has a closer genetic relationship with the AGPAT6 gene of cattle than with those of other species (Figure 7). 


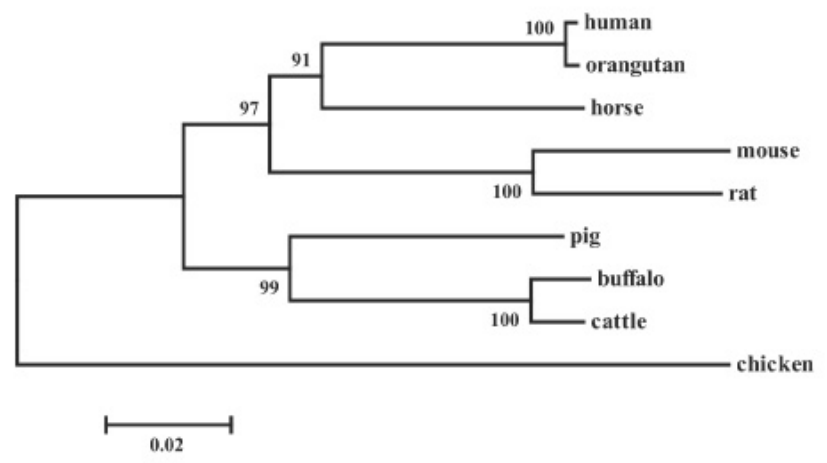

Figure 7. Neighbor-joining phylogenetic tree based on AGPAT6 gene among some species.

The complete CDS of the AGPAT6 gene and its deduced aa are presented in Figure 2. The deduced aa sequence of the water buffalo AGPAT6 gene shares 99, 98, 98, 97, 98, 98, 97, and $95 \%$ homology with that of cattle, horse, human, mouse, orangutan, pig, rat, and chicken, respectively. There are 24 nucleotide differences for the AGPAT6 coding region between water buffalo and cattle, of which three nonsynonymous ones were identified (viz., c.103 A>G, c. $520 \mathrm{~T}>\mathrm{C}$, and c.529 $\mathrm{T}>\mathrm{C}$ ). The c. $103 \mathrm{~A}>\mathrm{G}$ and c.529T $>\mathrm{C}$ cause the 35 th encoded amino acid of AGPAT6 to change from isoleucine to valine acid (p. I35V), and the 177th residue to change from proline to serine (p. P177S), respectively. Both involve a change from a nonpolar hydrophobic amino acid to a charged acidic amino acid. Another substitution is c. $520 \mathrm{~T}>\mathrm{C}$, which brings about the corresponding deduced amino acid p.174 F>L change. The homology trees for the deduced amino acid sequences of AGPAT6 revealed that water buffalo AGPAT6 has the highest identity to the cattle $A G P A T 6$ than to those of other species in our study (Figure 8).

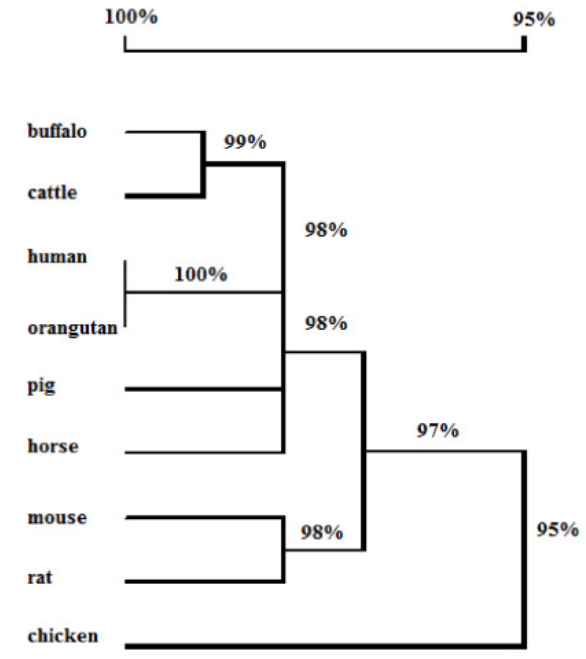

Figure 8. Homology tree based on the AGPAT6 amino acid sequences in some species. Water buffalo (accession No. AFV46336; this study), cattle (accession No. NP_001077138), human (accession No. NP_848934), orangutan (accession No. NP_001126531), pig (accession No. NP_001138491), horse (accession No. XP_001490154), mouse (accession No. NP_061213), rat (accession No. NP_001041314), chicken (accession No. XP_424400). 


\section{Potential microRNAs targets}

In this study, four microRNAs of B. taurus (viz., bta-miR-2439-5p, bta-miR-3431, btamiR-182, and bta-miR-16a) were found to have their target sites in the water buffalo AGPAT6 coding sequence. These are 776-ugacgucaucauccuggccag-756, 921-ccagaaggcugaccgag-905, 1213-agggugaagucugccaucgcca-1234, and 1087-agcagcaaguacggaauggug-1107, respectively.

\section{mRNA tissue expression profile}

To characterize the AGPAT6 gene further, we conducted RT-PCR to determine its expression level in various tissues. The ratio of the target band intensity of the AGPAT6 gene to the $18 \mathrm{~S}$ ribosomal RNA band intensity was used to represent the relative expression level of the target gene. The results revealed that the AGPAT6 gene was expressed in 12 of the water buffalo tissues tested with varying degrees. Among them, mammary gland had a high expression level, whereas heart, muscle, liver, and brain had moderate expressions; pituitary gland, spleen, and lung had lower expressions; and small intestine, skin, kidney, and adipose tissue had almost no expression (Figure 9).

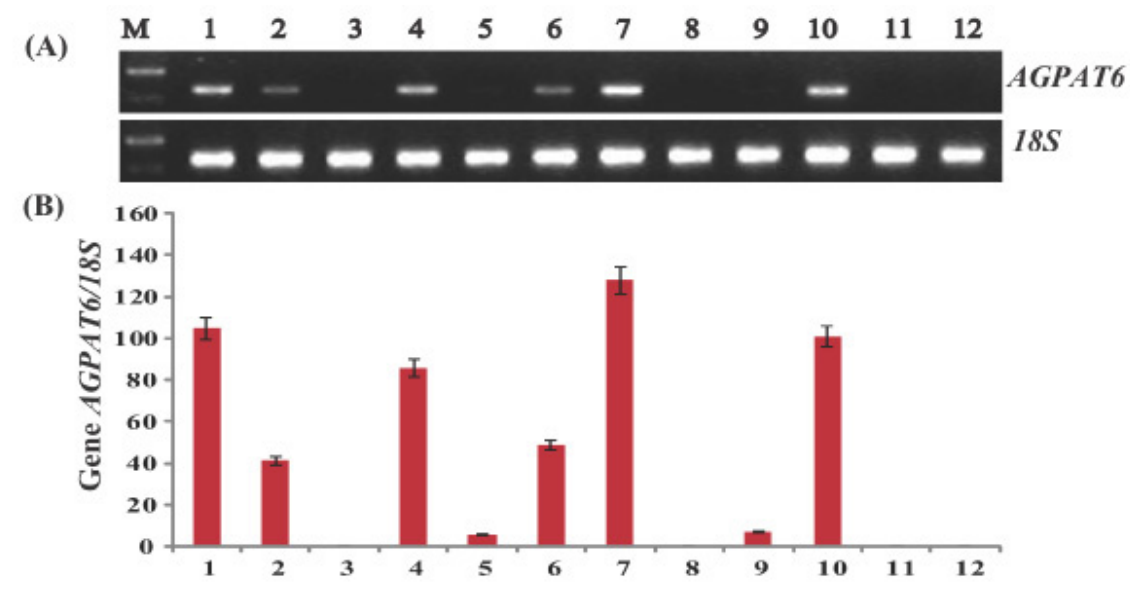

Figure 9. Tissue expression profile of water buffalo AGPAT6 gene. The 18S ribosomal RNA expression level was used as the internal control. A. Lane $1=$ heart; lane $2=$ pituitary gland; lane $3=$ small intestine; lane $4=$ muscle; lane $5=$ spleen; lane $6=$ liver; lane $7=$ mammary gland; lane $8=$ skin; lane $9=1$ ung; lane $10=$ brain; lane $11=$ kidney; lane 12 adipose tissue, and lane $M=$ DNA marker (DL2000). B. Columns related to the lanes above.

\section{DISCUSSION}

In this study, the full-length coding sequence of the AGPAT6 gene was cloned and characterized in water buffalo. It contains 1371 nucleotides encoding a putative protein of 456 aa, $52 \mathrm{kDa}$ in size, with a $\mathrm{pI}$ of 9.34. As in previous reports of human and mouse, the AGPAT6 protein in water buffalo also contains three hydrophobic transmembrane regions and a signal peptide of 37 aa, which implies that it is a transmembrane protein (Beigneux et al., 2006; Chen et al., 2008; Nagle et al., 2008). Generally, most protein functions are regulated by phosphorylation/dephosphorylation. In this study, several kinds of phosphorylation sites were found in 
the water buffalo AGPAT6, such as the protein kinase C phosphorylation site, casein kinase II phosphorylation site, and cAMP- and cGMP-dependent protein kinase phosphorylation sites. This indicates that AGPAT6 may play an important functional role through these sites and domains in water buffalo.

The results of homology analysis showed that water buffalo AGPAT6 has high identity to that of other mammals at the amino acid level, suggesting that the AGPAT6 protein is highly conserved among different species and has fundamental and critical effects on cell function. The phylogenetic tree analysis revealed that the water buffalo AGPAT6 gene has closer genetic relationships with the AGPAT6 gene in cattle. This implies that the AGPAT6 gene in water buffalo is more similar functionally to cattle.

In our study, four cattle microRNAs were found to have the corresponding target sites in the coding regions of water buffalo AGPAT6. MicroRNAs are noncoding single-stranded RNA molecules of 17 to 24 nucleotides that can regulate gene expression by binding to or regulating the translation process of some specific mRNAs (Zeng and Cullen, 2003; Bartel, 2004, 2009; Agarwal et al., 2006; Sukumaran et al., 2009). Whether these microRNA molecules predicted in this study can regulate the AGPAT6 gene expression in water buffalo requires further investigation.

AGPAT6 is broadly expressed and can be detected at the mRNA level in multiple tissues examined (Vergnes et al., 2006; Agarwal et al., 2007; Chen et al., 2008). In mouse, AGPAT6 is expressed at a high level in brown adipose tissue, white adipose tissue, liver, and mammary epithelium of breast tissue (Vergnes et al., 2006; Bionaz and Loor, 2008a). In our experiment, the AGPAT6 gene was obviously differentially expressed in the tissues detected, being especially highly expressed in mammary gland tissue. AGPAT6 has been found to be a crucial enzyme for the biosynthesis of glycerolipids and triacylglycerol in some mammalian tissues in recent years (Takeuchi and Reue, 2009). This implies that the AGPAT6 gene may play important roles for milk fat synthesis in water buffalo. The expression of AGPAT6 also changes with various physiological status in cattle. Previous studies in cattle showed that the mRNA abundance at 60 days postpartum for AGPAT6 increased by 15 -fold relative to 15 days antepartum (Bionaz and Loor, 2008a,b). As we have not yet studied AGPAT6 functions at protein levels, there may be many possible reasons for the differential expression of the AGPAT6 gene in water buffalo. The suitable explanation is that the biological activities associated with the functions of the AGPAT6 gene are presented diversely in different tissues and under different physiological states.

In conclusion, we first isolated the water buffalo AGPAT6 gene and then performed the necessary bioinformatics analysis and tissue transcription profile analysis. Furthermore, several microRNAs were found to have the corresponding target sites in the coding sequence of water buffalo AGPAT6 by theoretical prediction. This will establish the primary foundation for further insight into the structure and function of the AGPAT6 gene.

\section{ACKNOWLEDGMENTS}

Research supported by the Natural Science Foundation Key Project of Yunnan Province, China (\#2007C0003Z), the National Natural Science Foundation of China (\#30660024), the Applied and Basic Research Foundation of Yunnan Province, China (\#2006C0034M), and the Foundation of Yunnan Department of Finance, China (study on the germplasm characteristics of Binglangjiang water buffalo). 


\section{REFERENCES}

Agarwal AK, Barnes RI and Garg A (2006). Functional characterization of human 1-acylglycerol-3-phosphate acyltransferase isoform 8: cloning, tissue distribution, gene structure, and enzymatic activity. Arch. Biochem. Biophys. 449: 64-76.

Agarwal AK, Sukumaran S, Bartz R, Barnes RI, et al. (2007). Functional characterization of human 1-acylglycerol3-phosphate-O-acyltransferase isoform 9: cloning, tissue distribution, gene structure, and enzymatic activity. $J$. Endocrinol. 193: 445-457.

Aguado B and Campbell RD (1998). Characterization of a human lysophosphatidic acid acyltransferase that is encoded by a gene located in the class III region of the human major histocompatibility complex. J. Biol. Chem. 273: 4096-4105.

Bartel DP (2004). MicroRNAs: genomics, biogenesis, mechanism, and function. Cell 116: 281-297.

Bartel DP (2009). MicroRNAs: target recognition and regulatory functions. Cell 136: 215-233.

Beigneux AP, Vergnes L, Qiao X, Quatela S, et al. (2006). Agpat6 - a novel lipid biosynthetic gene required for triacylglycerol production in mammary epithelium. J. Lipid Res. 47: 734-744.

Bionaz M and Loor JJ (2008a). ACSL1, AGPAT6, FABP3, LPIN1, and SLC27A6 are the most abundant isoforms in bovine mammary tissue and their expression is affected by stage of lactation. J. Nutr. 138: 1019-1024.

Bionaz M and Loor JJ (2008b). Gene networks driving bovine milk fat synthesis during the lactation cycle. BMC Genomics 9: 366.

Chen YQ, Kuo MS, Li S, Bui HH, et al. (2008). AGPAT6 is a novel microsomal glycerol-3-phosphate acyltransferase. $J$. Biol. Chem. 283: 10048-10057.

Coleman RA and Lee DP (2004). Enzymes of triacylglycerol synthesis and their regulation. Prog. Lipid Res. 43: 134-176.

Khan FA, Nabi SU, Pande M, Das GK, et al. (2011). Bilateral follicular cysts in a water buffalo. Trop. Anim. Health Prod. 43: 539-541.

Li D, Yu L, Wu H, Shan Y, et al. (2003). Cloning and identification of the human LPAAT-zeta gene, a novel member of the lysophosphatidic acid acyltransferase family. J. Hum. Genet. 48: 438-442.

Mahmood A and Usman S (2010). A comparative study on the physicochemical parameters of milk samples collected from buffalo, cow, goat and sheep of gujrat, Pakistan. Pak. J. Nutr. 9: 1192-1197.

Möller S, Croning MD and Apweiler R (2001). Evaluation of methods for the prediction of membrane spanning regions. Bioinformatics 17: 646-653.

Nafikov R (2010). Genetic Regulation of Bovine Milk Fatty Acid Composition: Improving the Healthfulness of Milk Through Selection. Master's thesis, USI, Biochemistry, Biophysics and Molecular Biology.

Nagle CA, Vergnes L, Dejong H, Wang S, et al. (2008). Identification of a novel sn-glycerol-3-phosphate acyltransferase isoform, GPAT4, as the enzyme deficient in Agpat6-/- mice. J. Lipid Res. 49: 823-831.

Perera BM (2011). Reproductive cycles of buffalo. Anim. Reprod. Sci. 124: 194-199.

Singh J, Nanda AS and Adams GP (2000). The reproductive pattern and efficiency of female buffaloes. Anim. Reprod. Sci. 60-61: 593-604.

Sukumaran S, Barnes RI, Garg A and Agarwal AK (2009). Functional characterization of the human 1-acylglycerol3-phosphate-O-acyltransferase isoform 10/glycerol-3-phosphate acyltransferase isoform 3. J. Mol. Endocrinol. 42: 469-478.

Takeuchi K and Reue K (2009). Biochemistry, physiology, and genetics of GPAT, AGPAT, and lipin enzymes in triglyceride synthesis. Am. J. Physiol. Endocrinol. Metab. 296: E1195-E1209.

Vergnes L, Beigneux AP, Davis R, Watkins SM, et al. (2006). Agpat6 deficiency causes subdermal lipodystrophy and resistance to obesity. J. Lipid Res. 47: 745-754.

Vijh RK, Tantia MS, Mishra B and Bharani Kumar ST (2008). Genetic relationship and diversity analysis of Indian water buffalo (Bubalus bubalis). J. Anim. Sci. 86: 1495-1502.

Wang X, Wurmser C, Pausch H, Jung S, et al. (2012). Identification and dissection of four major QTL affecting milk fat content in the German Holstein-Friesian population. PLoS One 7: e40711.

Ye GM, Chen C, Huang S, Han DD, et al. (2005). Cloning and characterization a novel human 1-acyl-sn-glycerol-3phosphate acyltransferase gene AGPAT7. DNA Seq. 16: 386-390.

Yindee M, Vlamings BH, Wajjwalku W, Techakumphu M, et al. (2010). Y-chromosomal variation confirms independent domestications of swamp and river buffalo. Anim. Genet. 41: 433-435.

Zeng Y, Yi R and Cullen BR (2003). MicroRNAs and small interfering RNAs can inhibit mRNA expression by similar mechanisms. Proc. Natl. Acad. Sci. U. S. A. 100: 9779-9784.

Zimin AV, Delcher AL, Florea L, Kelley DR, et al. (2009). A whole-genome assembly of the domestic cow, Bos taurus. Genome Biol. 10: R42. 